\title{
Counterconditioning of shock by a water reinforcer in rabbits
}

\author{
MICHAEL F. DEARING \\ University of Sussex, Brighton, Sussex BN1 9QG, England \\ and \\ ANTHONY DICKINSON \\ University of Cambridge, Cambridge CB2 $2 E B$, England
}

\begin{abstract}
Three experiments studied the counterconditioning of certain properties of eyeshock in rabbits by establishing the shock as an appetitive CS for a jaw-movement response reinforced by intraoral water injections in a Pavlovian conditioning procedure. Although Experiment 1 demonstrated that such appetitive conditioning did not attenuate the unconditioned eyeblink elicited by the shock, it reduced the capacity of the shock to suppress leverpress responses reinforced by direct water injections in a signaled punishment procedure in Experiment 2. By contrast, when instrumentally reinforced licking was punished by eyeshock in Experiment 3 , no such reduction in the suppressive capacities of the shock was found. The results were considered in terms of whether counterconditioning alters the response-eliciting or motivational and reinforcing properties of the shock.
\end{abstract}

Erofeeva $(1916,1921)$, working in Pavlov's laboratory, reported that the defensive reactions to a primary aversive stimulus, shock, could be completely abolished in dogs by establishing it as a conditioned stimulus (CS) for an appetitive reinforcer, food. In other words, unconditioned defensive responses appeared to be susceptible to counterconditioning. The decline in defensive behavior was accompanied by the development of an alimentary conditioned response, salivation, to the shock, suggesting that appetitive conditioning may be an important causal factor underlying the successful counterconditioning of aversive stimuli. Subsequently, outside the Russian literature (e.g., Marukhanyan, 1954), little attention has been paid to the counterconditioning of the responses elicited by unconditioned aversive stimuli despite the theoretical importance of the phenomenon for understanding appetitive-aversive interactions (Dickinson \& Pearce, 1977).

By contrast, the counterconditioning of conditioned, as opposed to unconditioned, defensive responses has been somewhat more intensively studied (see Dickinson \& Pearce, 1977; Wilson \& Davison, 1971, for recent reviews). For example, Scavio (1974) initially conditioned a defensive nictitating membrane response to an auditory CS with a paraorbital

These experiments are based on a Masters thesis submitted by M. F. Dearing to the University of Sussex. M. F. Dearing was supported by a U.K. Medical Research Council studentship, and the work was also supported by the U.K. Science Research Council. Requests for reprints should be sent to Anthony Dickinson, The Psychological Laboratory, University of Cambridge, Downing Street, Cambridge CB2 3EB, England. shock reinforcer in rabbits. The shock was then omitted in a second, appetitive, conditioning stage, and the CS was paired with a water reinforcer for the experimental group. As the conditioned appetitive jaw-movement response was established, the defensive response declined. The fact that this decline tended to be greater for the experimental animals than for controls receiving either the CS and water unpaired or the CS alone suggests that conditioned defensive responses can be counterconditioned with an appetitive reinforcer.

The present studies investigated the counterconditioning of the properties of an unconditioned aversive stimulus, eyeshock, in a similar rabbit conditioning preparation. Experiment 1 investigated whether a paraorbital shock could be successfully established as an appetitive CS for the jaw-movement response, and whether such appetitive conditioning was accompanied by the attenuation of the defensive outereyelid closure elicited by the shock. In a similar experiment, Tait (1974) failed to find any evidence for a reduction in an unconditioned orbital defensive response in the presence of successful appetitive conditioning.

\section{EXPERIMENT 1}

\section{Subjects}

\section{Method}

The subjects were eight male New Zealand White rabbits (Oryctolagus cuniculus) between 4 and 5 months of age with a weight range of 2.4 to $3.0 \mathrm{~kg}$. They were housed individually and maintained on a water-deprivation schedule with free food available in their home cages. 


\section{Apparatus}

The conditioning apparatus for restraining the rabbits and measuring the defensive eyeblink and appetitive jaw-movement component of the swallowing reflex was a modified version of that pioneered and developed by Gormezano and his associates (Gormezano, 1966; Scavio, 1974). During conditioning, the rabbit was placed in a Perspex stock that lightly restrained gross body and head movements. Outer eyelid closures were measured by directing onto the center of the cornea of the right eye a galliumarsenide infrared source. The eyelid, on closing, reflected this source, and the reflected energy was detected by a phototransistor placed directly under the infrared source. Jaw movements were measured by passing a piano-wire lever through a stainless steel 9-mm autoclip attached to the tip of the rabbit's mandible. The lever was mechanically coupled to an opaque, rectangular, Perspex flag. In the resting position, the flag was between a light source and a light-sensitive cell. Jaw movements caused the flag to be raised and exposed the cell to light, giving a signal that was proportional to the displacement of the flag. The recording apparatus was mounted on a thread pillar of a brass headplate. The headplate was secured to the rabbit by two pieces of flexible copper tubing that fell either side of the animal's snout and by a circular ring of copper tubing that slipped over the animal's ears. Each of the two conditioning stocks was placed in a separate soundattenuating cubicle.

The signals from the recording apparatus were amplified and fed to the dc driver amplifiers of a Grass Model 7 polygraph. These signals were then displayed by the ink writing pens of the polygraph operating with a paper speed of $50 \mathrm{~mm} / \mathrm{sec}$.

A $2.0-\mathrm{ml}$ squirt of tap water could be delivered to the oral cavity of the rabbit over a period of $1.5 \mathrm{sec}$ from a reservoir via a length of polyethylene tubing. The tube was interrupted below the reservoir by a solenoid valve and terminated in a blunted No. 16 hypodermic needle. The water was introduced into the mouth by inserting the needle through a permanentiy implanted fistula in the rabbit's right cheek. Postorbital eyeshocks of $2.5-\mathrm{mA}$ intensity and 500 -msec duration could be delivered through alligator clips attached to two stainless steel 9-mm autoclips positioned $15 \mathrm{~mm}$ apart and $15 \mathrm{~mm}$ behind the rabbit's right eye. Modified Campden Instruments shock generators were used to provide the $50-\mathrm{Hz}$, pulsed, square-wave shocks.

\section{Procedure}

Several days after arrival, each rabbit was anaesthetized with $1.5 \mathrm{ml}$ of sodium pentobarbital (Nembutal veterinary with a strength of $60 \mathrm{mg} / \mathrm{ml}$ ) injected intraperitoneally. Two autoclip sutures were implanted behind the right eye and one on the tip of the lower mandible. The small permanent fistula to receive the water supply tube was then made in the right cheek following the procedure used by Smith, Dilollo, and Gormezano (1966). A cannula of PE-240 polyethylene tubing was passed through a hole in the cheek and retained in position by polyethylene washers on either side of the cheek. On the second postoperative day, the subjects were put on a water-deprivation regime of $80 \mathrm{ml} /$ day that included the water received during conditioning sessions. The following day, each rabbit was adapted to the experimental apparatus by being left in the stock for $60 \mathrm{~min}$ with the recording apparatus attached. Four rabbits were randomly assigned to one of two groups: paired and unpaired.

Animals in the paired group experienced a simple Pavlovian conditioning procedure in which they received a number of trials in which the shock CS was paired with the water reinforcer, interspersed with test trials with the shock alone. On paired trials, the onset of the shock preceded water delivery with an interstimulus interval of $1.0 \mathrm{sec}$. The intertrial interval was variable, with a mean of 2 min (range: 80-160 sec). Each 60-min session consisted of 30 trials, and was divided into six blocks of trials, each consisting of 4 paired trials and 1 test trial. On each session, the unpaired group received 30 trials in which the shock was presented alone and 24 trials in which the water was presented alone to equate the number of shock and water deliveries in the two groups.

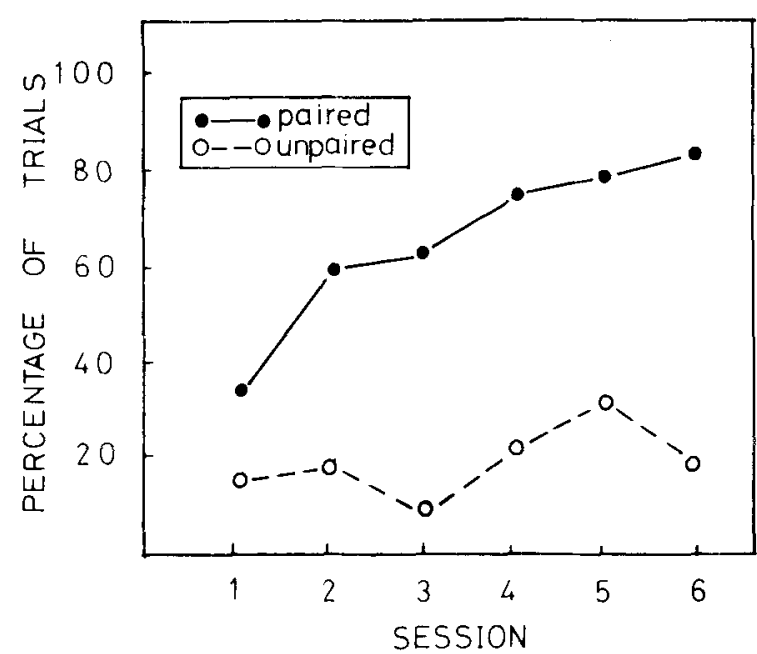

Figure 1. Experiment 1: Percentage of trials in each session on which a jaw movement occurred on shock-alone test trials for the paired group and on shock trials for the unpaired group.

The shock and water presentations were given in a random order with the constraint that not more than three of the same type could occur consecutively. The intertrial interval was variable, with a mean of 1 min (range: $40-80 \mathrm{sec}$ ). All animals received six conditioning sessions.

\section{Response Specification}

An eyeblink response was defined as an increment of at least $1.0 \mathrm{~mm}$ on the polygraph chart occurring within $500 \mathrm{msec}$ of shock onset. The latency was measured from the time of shock onset to the time when the response met this criterion, and the amplitude was defined as the maximum deviation of the response from the value at the time of shock onset. A jaw movement was defined as the occurrence of at least one point of inflection in the polygraph record where a point of inflection was an increment of at least $1 \mathrm{~mm}$ followed by a decrement of at least $1 \mathrm{~mm}$.

\section{Results and Discussion}

There was good evidence that jaw movements were conditioned to the shock $C S$ in the paired group. Figure 1 shows that the mean percentage of shockalone trials on which at least one jaw movement occurred within $2.5 \mathrm{sec}$ of shock onset was greater for the paired group than for the unpaired group $[F(1,6)$ $=33.6, \mathrm{p}<.01]$.

Figures 2 and 3, however, show that establishing the shock as a CS for an appetitive jaw movement failed to affect either the latency or amplitude of the unconditioned defensive responses elicited by the shock. In both groups, the shock elicited eyeblinks on all trials. An analysis of the reciprocal latencies revealed neither a significant effect of Group $(F<1)$ nor a significant Group by Session $(F<1)$. In a comparable analysis of the amplitude of the response, the effect of Group $(F<1)$ and the Group by Session interaction $(F<1)$ were both insignificant.

These results confirm the findings of Erofeeva $(1916,1921)$ and Tait (1974) that a potentially aversive stimulus can be successfully established as a CS for an appetitive response. In line with Tait's results, however, such conditioning does not necessarily lead 


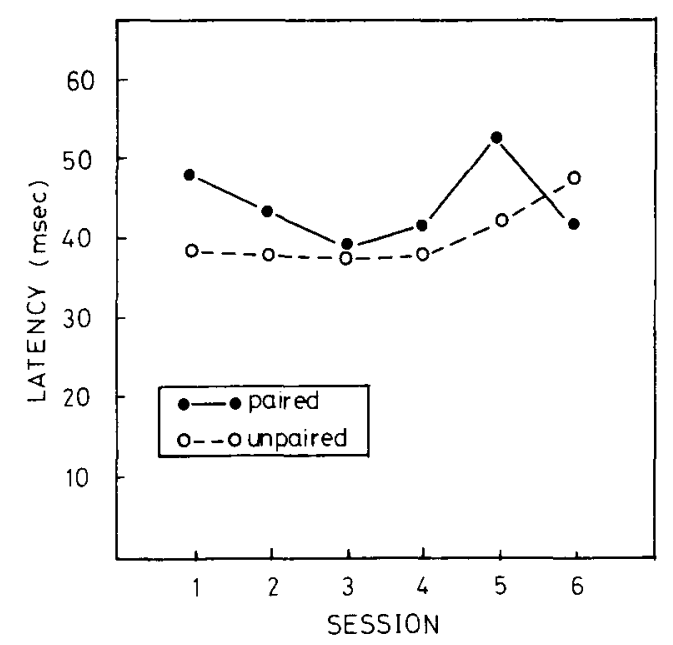

Figure 2. Experiment 1: Mean latency of the eyeblink to the shock in each session for the paired and unpaired groups.

to an attenuation of the unconditioned defensive response elicited by the aversive stimulus.

\section{EXPERIMENT 2}

The failure to countercondition the unconditioned responses elicited by an aversive stimulus does not necessarily mean that the general aversive properties of the shock remain unaltered by the appetitive conditioning procedure. In fact, a number of studies have shown that pairing shock with a positive reinforcer in an instrumental punishment procedure attenuates the capacity of the shock to suppress the instrumental response (Appel, 1968; Dickinson, 1975; Dickinson \& Pearce, 1976; Logan, 1960; Murray \& Nevin, 1967; Scull \& Veschler, 1972; Williams \& Barry, 1966). Similarly, shock-food pairing can also reduce the capacity of the shock to act as a Pavlovian reinforcer (Pearce \& Dickinson, 1975) and to maintain avoidance of a location in which the shock is delivered (Dickinson \& Pearce, 1976). None of these studies, however, provided any independent evidence that the counterconditioning procedure established the shock as an appetitive CS. This experiment sought to investigate whether the appetitive conditioning procedure used in Experiment 1 changed the general aversive properties of the eyeshock as measured by its capacity to suppress an instrumental response in a punishment procedure.

\section{Subjects and Apparatus}

\section{Method}

Twelve male rabbits of comparable weight and age to those employed in Experiment 1 were used. The apparatus was the same as that used in Experiment 1 . In addition, a 2,000- $\mathrm{Hz}$ tone could be presented from a speaker mounted $15 \mathrm{~cm}$ above the animal's head. Presentation of the tone increased the noise level in the chamber by approximately $5 \mathrm{~dB}$ from a background value of $70 \mathrm{~dB}$ (re: $20 \mu \mathrm{N} / \mathrm{m}^{2}$ ). An inverted Campden Instruments rat lever could also be positioned in front of the animal. The lever was balanced and positioned so that a slight upward movement of the snout while the animal was in the stock with the recording appa- ratus operated the lever. Shock and water delivery did not cause the animal to operate the lever. Each leverpress operated a relay in the experimental chamber to provide auditory feedback for responses.

\section{Procedure}

Baseline instrumental training. The operative procedure and deprivation schedule were the same as those employed in Experiment 1 . On the 3 rd postoperative day, each rabbit was adapted to the experimental apparatus without the lever or recording apparatus for a 40-min session. On the next day, a second adaptation session with the recording apparatus was given. The lever was then positioned in front of the animal, and training was begun to establish the instrumental leverpress response. On the first three sessions, leverpresses were reinforced on a fixed interval (FI) $10-\mathrm{sec}$ schedule with a $2.0-\mathrm{ml}$ squirt of water delivered directly into the rabbit's oral cavity. Leverpresses were then reinforced on a variable interval (VI) 30 -sec schedule for four sessions followed by a further four sessions with a VI 60 -sec schedule.

Determination of shock intensity and duration. The aim of the next stage was to establish the parameters for the eyeshock that would produce significant suppression in a signaled punishment procedure. Throughout this stage, leverpresses were reinforced on the VI 60 -sec schedule of water reinforcement. In the first 40 -min session, a 70-sec tone was presented alone five times, with an intertrial interval of $7 \mathrm{~min}$, to test for any unconditioned suppression. On the following day, the signaled punishment procedure began with the eyeshock being delivered only during the tone on an FI 15-sec schedule. For the duration of the tone, the programs determining the VI 60 -sec schedule of water reinforcement and the FI 15-sec schedule of shock presentation were running concurrently. When a shock or water reinforcer was programmed to occur, both programs stopped timing the intervals until the event was delivered. This prevented any spurious pairings of the shock and water when the animals suppressed responding.

To control for individual differences in the overall rate of leverpressing, suppression was indexed by a suppression ratio which equaled $A /(A+B)$, where $A$ is the rate of responding during the tone and $B$ the rate of responding during a $70-\mathrm{sec}$ period immediately preceding the tone. The ratio has a value of zero when there is complete suppression of responding and a value of .5 in the absence of any suppression. The intensity and duration of the shock was progressively increased until all rabbits had a criterion suppression ratio of .3 or less. For the first five sessions, a shock of $4.5-\mathrm{mA}$ intensity and $600-\mathrm{msec}$ duration was used. On the next session, the intensity was increased to $5.0 \mathrm{~mA}$, and on the final session, both the intensity and duration were increased to $6.0 \mathrm{~mA}$ and $700 \mathrm{msec}$, respectively. On this session, all animals

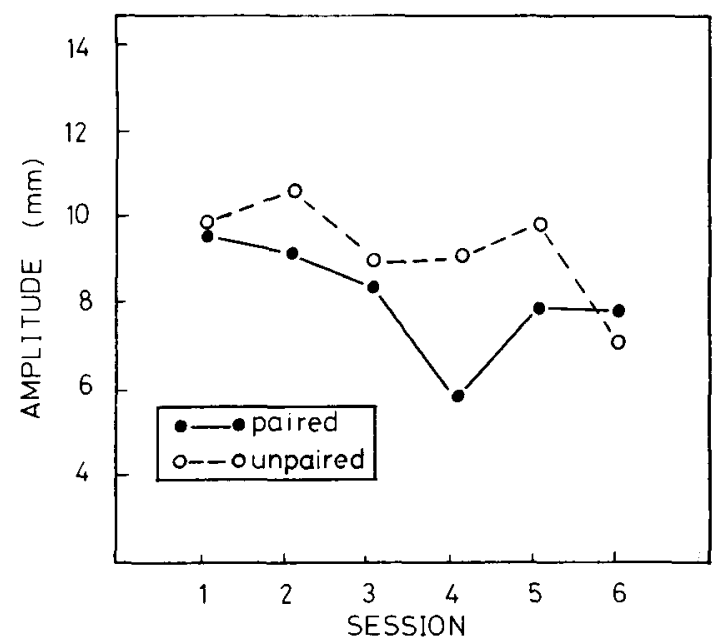

Figure 3. Experiment 1: Mean amplitude of the eyeblink to the shock in each session for the paired and unpaired groups. 
achieved the criterion suppression, and the associated shock parameters were used throughout the rest of the experiment.

This stage was concluded by extinguishing suppression to the tone; five tone presentations were given in the absence of any punishment in each of four sessions.

Pavlovian counterconditioning. The lever was removed, and the animals were divided into a paired group $(\mathrm{N}=6)$ and an unpaired group $(\mathrm{N}=6)$ for 10 daily 45 -min sessions of counterconditioning. The procedure was similar to that experienced by the equivalent groups in Experiment 1 . The paired group received 15 shock-water pairings during each session, with the onset of the shock preceding that of the water by an interstimulus interval of $700 \mathrm{msec}$. As in the previous stage, the shock had an intensity of $6.0 \mathrm{~mA}$ and a duration of $700 \mathrm{msec}$ and the water reinforcer consisted of a 2.0-ml injection over a 1.5 -sec period. A variable intertrial interval with a mean of $3 \mathrm{~min}$ (range 2-4 min) was used. The unpaired group received exactly the same number of shocks and water injections, but unpaired and in a random order, with the constraint that not more than three presentations of the same event could occur consecutively. The intertrial interval was variable, with a mean of $1.5 \mathrm{~min}$ (range $1.2 \mathrm{~min}$ ). Finally, at the end of each of the last five sessions of counterconditioning, a test shock was presented alone to each animal.

Signaled punishment test. On the next session, the lever was replaced and pressing was reestablished on the VI $60-\mathrm{sec}$ schedule. During this pretest session, five tone presentations were given in the absence of punishment to extinguish any spontaneous recovery of suppression. This was followed by five sessions of signaled punishment, using exactly the same procedure as previously with the same shock parameters as employed during counterconditioning.

\section{Results and Discussion}

During the last 4 days of baseline training, the mean leverpress rates of the paired and unpaired groups were 4.3 and 5.6 responses/min, respectively, which did not differ significantly $(F<1)$. An analysis of the suppression ratios during the first stage of signaled punishment when the shock parameters were varied revealed a significant decrease over sessions $[F(6,60)=4.43, p<.05]$, no significant effect of Group $[F(1,10)=1.85, \mathrm{p}>.10]$, and no significant Group by Session interaction $[F(6,60)=1.48$, $p>.10]$. Similarly during the sessions in which suppression was extinguished, the ratios of the two groups did not differ significantly $[\mathrm{F}(1,10)=2.07$, $\mathrm{p}>.10 \mathrm{j}$. On the last extinction session, the mean suppression ratios of the paired and unpaired groups were .49 and .47 , respectively.

The results of the Pavlovian counterconditioning stage essentially replicated those of Experiment 1; the jaw-movement response was successfully conditioned to the eyeshock, but there were no significant changes in either the latency or amplitude of the eyeblink to the shock. Over the five test shocks, the paired groups showed a jaw movement during a 2.2-sec period after the onset of the shock on $60 \%$ of trials, whereas the shock elicited a jaw movement on only $4 \%$ of the trials in the unpaired group [Mann-Whitney U-test $U=1, p<.01$ ]. The latency and amplitude of the eyeblink elicited by the shock did not differ for the two groups. The mean latency was $34 \mathrm{msec}$ for the paired group and $36 \mathrm{msec}$ for the

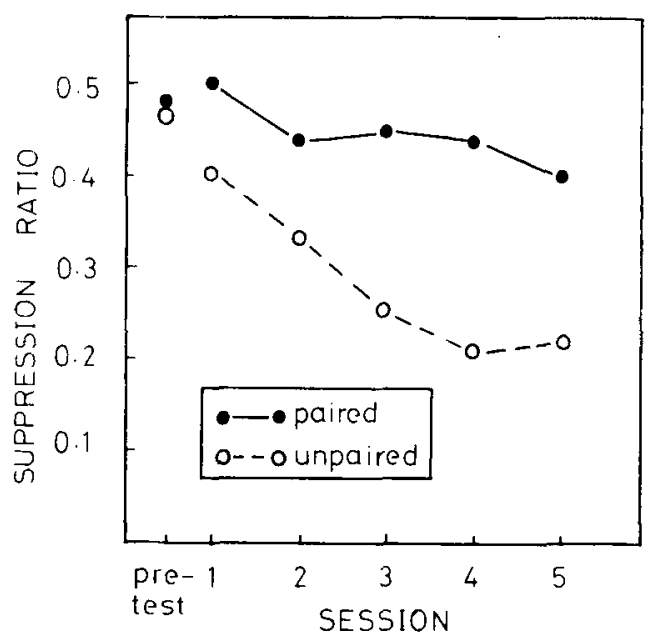

Figure 4. Experiment 2: Mean suppression ratios during the pretest session and the signaled punishment sessions for paired and unpaired groups.

unpaired group. An analysis of the reciprocal latencies revealed neither a significant effect of Group [F $<1]$ nor a significant Group by Session interaction $[F(9,90)=1.05, p>.25]$. The mean amplitude of the eyeblink was $8.1 \mathrm{~mm}$ for the paired group and $9.8 \mathrm{~mm}$ for the unpaired group. The difference in amplitude was not significant $[\mathrm{F}(1,10)=2.74$, $\mathrm{p}>$ $.10]$, nor was the Group by Session interaction $(\mathrm{F}<1)$.

The results of prime interest are displayed in Figure 4 , which illustrates the mean suppression ratios of the two groups on the pretest session for spontaneous recovery and during the signaled punishment sessions after counterconditioning. The tone elicited very little suppression on the pretest session, which did not differ in the two groups $[\mathrm{t}(10)=1.32$, $\mathrm{p}>.10]$. By contrast, the paired group showed less suppression than the unpaired group during the punishment sessions. There was a significant effect of both Group $[\mathrm{F}(1,10)=13.15, \mathrm{p}<.01]$ and Session $[F(4,40)=10.40, p<.01]$, but no significant Group by Session interaction $[F(4,40)=2.50, p>.05]$. The mean pretrial response rates of the paired and unpaired group during the punishment sessions were 7.2 and 5.8 responses/min, respectively, which did not differ significantly $(\mathrm{F}<1)$.

These findings essentially confirm the results of the previous studies showing that pairing shock and an appetitive reinforcer will attenuate the capacity of the shock to act as an instrumental punisher. Furthermore, the present experiment provides direct evidence that such counterconditioning occurs within a context in which the shock is established as a CS capable of eliciting an appetitive conditioned response.

\section{EXPERIMENT 3}

The finding that programming an aversive stimulus so that it is a potential appetitive CS attenuates 
its capacity to act as a punisher is not universal. Hartlep and Bertsch (1974) found that if an instrumental licking response in rats was punished with a shock, the degree of suppression was unaffected by whether the shock was delivered just before, simultaneously with, or just after the water reinforcer, even though the shock should have become a more potent appetitive CS with forward pairings. This finding stands in marked contrast to the results of Experiment 2 and the other studies of the counterconditioning of suppressive properties of shock. As there is some evidence that primary aversive stimuli, such as shock, can, under certain circumstances, facilitate consummatory responding (see Myer, 1971), Hartlep and Bertsch's failure to countercondition the suppressive properties of shock might lie with their use of an instrumental response that is similar in form to a consummatory behavior. Alternatively, the failure of the counterconditioning might simply be due to the fact that their procedure did not successfully establish the shock as an appetitive CS. To investigate whether the suppressive properties of shock on a response with a consummatory form could be successfully counterconditioned when the shock was clearly established as an appetitive CS, the present study replicated the basic design of Experiment 2 except that the leverpress response was replaced by licking.

\section{Subjects and Apparatus}

\section{Method}

Ten rabbits of comparable weight and age to those employed in the previous experiments were used. The results of one rabbit that died during the course of the experiment have not been included in the presentation and analysis. The apparatus was the same as that used in Experiment 2, except that during instrumental training, the lever was replaced by a Perspex panel from which protruded a blunted hypodermic needle with a small brass ball soldered on the end. This was positioned close enough for the animal to lick but not hold in its mouth. Contact with the brass ball by the rabbit's tongue completed a drinkometer circuit and was counted as a response. Shock and water delivery did not result in the animal's making contact with the ball.

\section{Procedure}

The deprivation regime, surgical procedure, and basic design of the experiment were the same as those employed in Experiment 2. During initial baseline training, the licking response was reinforced on a VI 60 -sec schedule by a $2.0-\mathrm{ml}$ squirt of water into the intraoral cavity for 1540 -min sessions. In order to determine the shock parameters that would suppress responding, a signaled punishment procedure was then introduced. The punishment procedure was exactly the same as that employed in Experiment 2, except that in the present experiment the instrumental response was punished on a FI 30-sec schedule rather than the FI 15-sec schedule used in Experiment 2. As there is evidence that instrumental licking is more susceptible to punishment than leverpressing (Bertsch, 1972), a punishment schedule was used that delivered a lower frequency of shocks than the schedule employed in the previous study in an attempt to produce a comparable level of suppression in the two experiments with the same shock parameters. The intensity and duration of the eyeshock were progressively increased across sessions, as in Experiment 2, until all the animals showed a suppression ratio of .30 or less. This level of suppression was achieved with a $6.0-\mathrm{mA} 700$-msec shock, and these shock param- eters, which were the same as those employed in Experiment 2, were used throughout the rest of the study. This stage was concluded by extinguishing suppression to the tone during nine sessions, each containing five tone presentations in the absence of punishment.

The rabbits were then divided into a paired group $(\mathrm{N}=5)$ and an unpaired group $(\mathrm{N}=4)$, and received 20 sessions of Pavlovian counterconditioning with the licking apparatus removed, followed by a signaled punishment test with the licking apparatus present; the procedure during both these stages was identical to that employed in Experiment 2, except that the shocks were delivered on the FI $30-\mathrm{sec}$ schedule during the present punishment sessions. Unfortunately, there was no evidence that the shock was effective in suppressing responding during the signaled punishment test; the effect of Session on the suppression ratios $[F(4,28)$ $=1.87, \mathrm{p}>.10]$ and the Group by Session interaction $(\mathrm{F}<1)$ were both insignificant. The mean suppression ratios of the two groups during the signaled punishment sessions were identical, .36 , and on no session did the mean suppression ratio of either group drop below .30 . In the absence of significant suppression in either group, it is impossible to interpret the failure to find a significant difference between the level of suppression developed by the two groups.

Consequently, the Pavlovian counterconditioning and signaled punishment procedures were repeated using a punishment schedule that programmed a higher frequency of shocks than the schedule employed in the first signaled punishment test. On the day following the first signaled punishment test, the licking apparatus was removed and the rabbits were given three further sessions of counterconditioning in which the paired and unpaired groups received exactly the same schedule of events as during the first counterconditioning stage. On each of the last two sessions, a test shock was presented alone to assess the level of appetitive conditioning. The licking apparatus was then returned, and the rabbits were exposed to the second signaled punishment test. Initially, the tone was presented five times during each of three pretest sessions to extinguish any suppression that transferred from the first punishment stage. Five sessions of signaled punishment followed, using the same procedure as in the first punishment stage, except that the shock was now delivered on an FI 15 -sec schedule, as in Experiment 2 , in an attempt to increase the degree to which the shock suppressed licking during the tone.

\section{Results and Discussion}

All animals developed sustained levels of instrumental licking. The mean rate of licking over the last five sessions of baseline training was 14.5 responses/ $\min$ for the paired group and 13.4 responses/min for the unpaired group, which did not differ significantly $(F<1)$.

Due to the lack of suppression in the first punishment stage, we shall report only the results from the second Pavlovian counterconditioning and punishment stages. At the end of the second counterconditioning stage, the test shocks elicited jaw-movement responses on $100 \%$ of trials for the paired group and on $12.5 \%$ of trials for the unpaired group [U $=0$, $p<.02$ ]. The latencies and amplitude of the eyeblink response elicited by the shock did not differ for the two groups. The mean latency for the paired group was $30 \mathrm{msec}$ and for the unpaired group, $31 \mathrm{msec}$. There was no significant effect of Group $(F<1)$ and no significant Group by Session interaction $(F<1)$ for the reciprocal latencies. The mean amplitude of the eyeblinks was $8.7 \mathrm{~mm}$ for the paired group and $11.5 \mathrm{~mm}$ for the unpaired group. Again, there was 
no significant effect of Group $[F(1,7)=1.78, p>$ $.10]$ and no significant Group by Session interaction $(\mathrm{F}<1)$.

Figure 5 illustrates the mean suppression ratios during the last pretest extinction session, when the tone was presented in the absence of shock, and during the five signaled punishment sessions. During the pretest sessions, there was no significant effect of Group $[F(1,7)=1.27, p>.25]$ and no significant Group by Session interaction $[\mathrm{F}(2,14)=1.85, \mathrm{p}>$ .10]. During the punishment sessions, both groups showed an increase in the level of suppression $[\mathrm{F}(4,28)$ $=4.48, \mathrm{p}<.05$ ], until by the final session the mean ratios for both groups were below .30 . By contrast to Experiment 2, however, there was no indication that the suppressive capacity of the shock was attenuated in the paired group; in fact, the paired group consistently showed a lower mean suppression ratio than the unpaired group, although the difference was not significant. The effect of Group $(F<1)$ and the Group by Session interaction $[\mathrm{F}(4,28)=1.32$, $\mathrm{p}>$ .25 ] were both insignificant. The mean pretrial licking rates of the paired and unpaired groups during the punishment sessions were 32.0 and 32.4 responses/min, respectively $(\mathrm{F}<1)$.

The results of this experiment stand in marked contrast to those of Experiment 2. A conditioning procedure that established the shock as an appetitive CS for the paired group and attenuated its suppressive capacity for leverpressing appeared to have no effect on the potency of shock as punisher of a licking response under exactly the same parameters of counterconditioning and signaled punishment. However, the results of the two experiments should only be directly compared with caution, for not only did the experiments differ in the type of instrumental response employed but also in the extent to which the animals

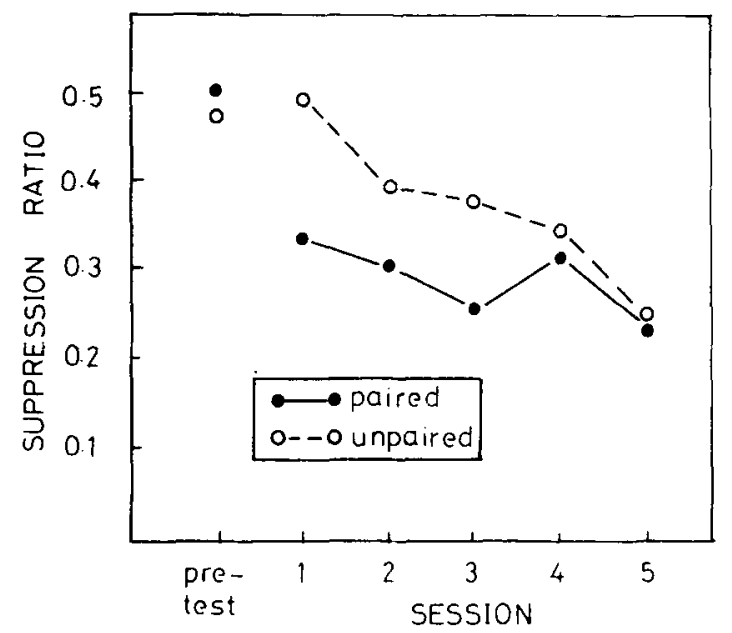

Figure 5. Experiment 3: Mean suppression ratios during the last pretest session and the signaled punishment sessions for the paired and unpaired groups. were exposed to the counterconditioning and punishment procedures and in the rate at which the baseline instrumental response was emitted.

\section{GENERAL DISCUSSION}

We wish to draw two main conclusions from these experiments. First, establishing a shock as an appetitive CS attenuates its capacity to punish behavior maintained by an instrumental contingency for leverpressing but not for licking. Secondly, such a reduction in the capacity of shock to punish responding is not necessarily accompanied by a decrement in the unconditioned defensive responses elicited by the shock. This is not to say that counterconditioning cannot attenuate unconditioned reactions, for it is possible that such a decrement was obscured by a "ceiling" effect in the present experiments. If a less intense shock had been employed, the defensive responses might well have been reduced.

It now remains for us to consider how these conclusions relate to current theories of counterconditioning. Dickinson and Pearce (1976) suggested that two main properties of an aversive stimulus might be altered by counterconditioning; response-eliciting properties and reinforcing or motivational properties. The "competing response" theory of punishment (see Church, 1963) points to a possible role for a change in the response-eliciting properties of the aversive stimulus in the attenuation of punishment. This theory proposes that behavior elicited by a punishing stimulus will become conditioned to stimuli accompanying the punished response and that this behavior will suppress the punished response by interference if they are incompatible. To explain the present results, the theory would have to assume that a counterconditioned shock elicits a complex of responses that is more compatible with leverpressing, but not licking, than the complex elicited by an unpaired shock. Although there is no doubt that the counterconditioned shock did elicit a different response pattern, of which jaw movements were one component, the main problem with this theory is that there is no a priori way of deciding whether a particular pattern of elicited responses is more or less compatible with the target instrumental response. The failure of the counterconditioning procedure to attenuate the eyeblink response evoked by the shock provides no difficulty, as Scavio (1974) has presented good evidence that orbital defensive responses and jaw movement are independent at a peripheral level.

The second account focuses on changes in the reinforcing properties of the shock as a result of counterconditioning. For instance, the shock might well be expected to acquire conditioned reinforcing properties in the paired condition which might then provide an added source of positive reinforcement to coun- 
teract the suppressive effects of the shock. Although there are certain difficulties in providing a general account of counterconditioning in these terms (see Dickinson \& Pearce, 1976), the only problem for the theory in the present case is that it provides no explanation of why the effectiveness of counterconditioning should depend upon the type of instrumental response employed. The failure to observe a change in the shock-elicited response is congruent with this account, for there is no obvious reason why establishing the shock as a conditioned reinforcer should alter its ability to control unconditioned defensive behavior.

An alternative motivational explanation assumes that counterconditioning directly reduces the intrinsic affective or motivational properties of the shock underlying its capacity to act as a punisher. This view is compatible with the idea that the central mechanisms mediating the motivational and reinforcing properties of appetitive and aversive stimuli form an opponent-process, with each system exerting an inhibitory influence on the other (see Dickinson \& Dearing, in press, and Dickinson \& Pearce, 1977, for recent expositions and evaluation of this idea). A potentially noxious stimulus loses its aversive character because counterconditioning enables the stimulus not only to activate the aversive system via an unconditioned route but also simultaneously the appetitive system via a conditioned route. Arousal of the appetitive system will then attenuate activity in the aversive system. Once again, this account provides no ready explanation of why the effectiveness of counterconditioning should depend upon the type of instrumental response employed and of the insensitivity of unconditioned defensive responses to counterconditioning. In fact, if counterconditioning attenuates the aversive character of the shock, the opponentprocess model would predict a diminution of the defensive responses elicited by the shock as well as a decrement in its capacity to act as a punisher.

The present results do not allow us to distinguish clearly between the various explanations of counterconditioning. What they do demonstrate, though, is that establishing a primary aversive stimulus as a Pavlovian CS for a reinforcer of opposite affective polarity can radically change the capacity of that stimulus to modulate certain types of instrumental behavior.

\section{REFERENCES}

APPEL, J. B, Association of aversive and reinforcing stimuli during intermittent punishment. Psychological Reports, 1968, 22, 267-271.

BERTSCH, G. Punishment of consummatory and instrumental behavior: Effects on licking and bar pressing in rats. Journal of Comparative and Physiological Psychology, 1972, 78, 478-484.
Church, R. M. The varied effects of punishment on behavior. Psychological Review, 1963, 70, 369-402.

Dickinson, A. Suppressive and enhancing effects of footshock on food-reinforced operant responding following septal lesions in rats. Journal of Comparative and Physiological Psychology, 1975, 88, 851-861.

Dickinson, A., \& Dearing, M. F. Appetitive-aversive interactions and inhibitory processes. In A. Dickinson \& R. A. Boakes (Eds.), Mechanisms of learning and motivation: Memorial volume for Jerzy Konorski. Hillsdale, N.J: Erlbaum, in press.

Dickinson, A., \& Pearce, J. M. Preference and response suppression under different correlations between shock and a positive reinforcer in rats. Learning \& Motivation, 1976, 7, 66-85.

Dickinson, A., \& PEARCE, J. M. Inhibitory interactions between appetitive and aversive stimuli. Psychological Bulletin, 1977, 84, 690-711.

Erofeeva, M. N. Contributions à l'étude des réflexes conditionnels destructifs. Compte Rendu de la Société de Biologie Paris, 1916, 79, 239-240.

Erofeeva, M. N. [Additional data on nocuous conditioned reflexes.] Izvestiga Petrogradskogo Nauchnago Instituta in P. F. Lesgafta, 1921, 3, 69-73. (Russian)

Gormezano, I. Classical conditioning. In J. B. Sidowski (Ed.), Experimental methods and instrumentation in psychology. New York: McGraw-Hill, 1966.

Hartle P, K., \& Bertsch, G. Facilitation of licking by responsecontingent electric shock. Animal Learning \& Behavior, 1974, 2, 196-198.

Logan, F. A. Incentive. New Haven: Yale University Press, 1960.

Marukhanyan, E. V. [The effect of the duration and intensity of a conditioned electroshock stimulus upon the magnitude of the conditioned food and acid reflexes.] Zhurnal Vysshei Nervnoi Deyatel'nosti, 1954, 4, 684-691. (Russian)

Murray, M., \& Nevin, J. A. Some effects of correlation between response-contingent shock and reinforcement. Journal of the Experimental Analysis of Behavior, 1967, 10, 301-309.

MYER, J. S. Some effects of noncontingent aversive stimulation. In F. R. Brush (Ed.), Aversive conditioning and learning. New York: Academic Press, 1971.

Pearce, J. M., \& Dickinson, A. Pavlovian counterconditioning: Changing the suppressive properties of shock by association with food. Journal of Experimental Psychology: Animal Behavior Processes, 1975, 1, 170-177.

Scavio, M. J., JR. Classical-classical transfer: Effects of prior aversive conditioning upon appetitive conditioning in rabbits. Journal of Comparative and Physiological Psychology, 1974, 86, 107-115.

Scull, J. W., \& Vechsler, D. Effects of positively and negatively correlated shock and reward on acquisition in the runway. Psychonomic Science, 1972, 27, 18-20.

Smith, M. C., Dilollo, V., \& Gormezano, I. Conditioned jaw movement in the rabbit. Journal of Comparative and Physiological Psychology, 1966, 62, 479-483.

TAIT, R. W. Assessment of the bidirectional conditioning hypothesis through the UCS $-U C S_{2}$ conditioning paradigm. Unpublished doctoral dissertation, University of Iowa, 1974.

Williams, D. R., \& BarRY, H., III. Counterconditioning in an operant conflict situation. Journal of Comparative and Physiological Psychology, 1966, 61, 154-156.

Wilson, G. T., \& Davison, G. C. Processes of fear reduction in systematic desensitization: Animal studies. Psychological Bulletin, 1971, 76, 1-14.

(Received for publication June 1, 1978; revision accepted November 14, 1978.) 